\title{
Emotional impact of dissection hall on medical students
}

\author{
Ritu Singroha', Usha Verma ${ }^{2}$, Preeti Malik³, Pankaj Chhikara ${ }^{4}$, Suman Yadav ${ }^{3}$ \\ ${ }^{1}$ Associate Professor, ${ }^{2}$ Assistant Professor, ${ }^{3}$ Demonstrator, Department of Anatomy, ${ }^{4}$ Assistant Professor, Department \\ of Forensic Medicine, Pt. B.D. Sharma PGIMS, Rohtak, Haryana, India
}

Background: Dissection of the dead human body has been central to medical education since Renaissance. First year medical students normally experience a variety of emotional reactions and mixed feelings, when they encounter human cadavers for the first time. Aims and Objective: First year medical students normally experience a variety of emotional reactions and mixed feelings, when they encounter human cadavers for the first time. The aim of the study was to study the difference in dissection hall experience of the male and female medical students over a period of time. Material and Methods: Total 178 students were given a questionnaire within 3-4 days and again 3 months after the start of dissection in the dissection hall. The students were asked to answer in either 'Yes' or 'No' option. Results: All the symptoms were found to be decreased in both male and female students over a period of 3 months except lack of concentration in males. No statistical significant difference was found between the symptoms of male and female students. Conclusion: A better teacher - student interaction, pre-education sessions will help in improving the attitudes of students towards cadaveric dissection, thereby reducing the drop-out rates.

Key words: Dissection, Renaissance, Cadaver, Medical students

\section{INTRODUCTION}

Dissection of the dead human body has been central to medical education since Renaissance. ${ }^{1,2}$ Indeed, the Greek roots of the word anatomy indicate cutting up, ${ }^{2}$ so many anatomists are adamant that dissection is the best way to anatomy learning. ${ }^{1,2}$ Anatomical knowledge remains a cornerstone of medicine and related professions inspite of reductions in the importance, time committed to, and status of anatomical education in modern curricula. ${ }^{3}$ Dissection brings the students to the closest and most comprehensive encounter with human mortality. It helps in developing a spatial and tactile appreciation for the fabric of the human body. Cadaver Dissection has been called the "sharp-end" of medical education. Dissection has also been labeled as the "royal road" and cadaver as the "first patient".

Dissection of a human body during an anatomy course raises for first-year medical students questions about invasion of privacy, cadaver sources, dying and death. ${ }^{5}$ First year medical students normally experience a variety of emotional reactions and mixed feelings, when they encounter human cadavers for the first time. ${ }^{6}$ A medical student reports that: "the first cut through the skin (of a cadaver) is really bad, but when you get down there and it begins to look like the anatomy book and it doesn't look like a human being anymore, it's not so bad".

There are varying responses as regards students attitudes and views towards cadaver dissection. In order to assess the impact of anxiety and physical symptoms from the experience of dissection room, we prepared a questionnaire to study the difference in emotional impact related to dissection hall experience of male and female medical students and to study the change in this emotional impact on initial exposure and after 3 months.

\section{MATERIAL AND METHODS}

The present study was conducted on 178 first professional medical students at Pt. B.D. Sharma Post Graduate Institute 
of Medical Sciences, Rohtak (Haryana) in 2014-2015. The students were informed about the study and their consent was duly taken. Any chance of participant bias was eliminated by clearly explaining to all participants the objective of the study while obtaining their written informed consent (Table 1). All the 178 students were given a questionnaire within 3-4 days of the start of dissection in the dissection hall (Table 2). This questionnaire was again repeated after a period of 3 months. The questionnaire contained information regarding age, gender and address and presence or absence of symptoms related to dissection. The students were asked to answer in either 'Yes' or 'No' option.

\section{Statistical analysis}

Data obtained was analysed using SPSS 17.1 software. The Chi-square and Fisher's exact test were employed in the assessment of differences in emotional impact of dissection between:-

- Males and Females.

- Initial Exposure and After 3 months.

$\mathrm{p}$-value $\leq 0.05$ was considered significant.

\begin{tabular}{|c|c|c|c|c|}
\hline S.No. & Symptoms & $\begin{array}{l}\text { Within } \\
3-4 \text { days } \\
(\%)\end{array}$ & $\begin{array}{c}\text { After } \\
3 \text { months } \\
(\%)\end{array}$ & $p$-value \\
\hline 1. & $\begin{array}{l}\text { Difficulty in } \\
\text { consuming food }\end{array}$ & $8(10.4)$ & $7(9.1)$ & 0.78 \\
\hline 2. & Nausea & $7(9.1)$ & $3(3.9)$ & 0.19 \\
\hline 3. & Horrifying dreams & $5(6.5)$ & $2(2.6)$ & 0.44 \\
\hline 4. & Dizziness & $4(5.2)$ & $1(1.3)$ & 0.36 \\
\hline 5. & Shivering of hands & $0(0)$ & $0(0)$ & - \\
\hline 6. & Fright & $3(3.9)$ & $0(0)$ & - \\
\hline 7. & $\begin{array}{l}\text { Lack of } \\
\text { concentration }\end{array}$ & $4(5.2)$ & $3(3.9)$ & 0.50 \\
\hline 8. & $\begin{array}{l}\text { Sleep } \\
\text { disturbances }\end{array}$ & $6(7.8)$ & $0(0)$ & - \\
\hline
\end{tabular}

\begin{tabular}{|c|c|c|c|c|}
\hline S.No. & Symptoms & $\begin{array}{l}\text { Within } \\
3-4 \text { days } \\
\text { (\%) }\end{array}$ & $\begin{array}{c}\text { After } \\
3 \text { months } \\
(\%)\end{array}$ & $p$-value \\
\hline 1. & $\begin{array}{l}\text { Difficulty in } \\
\text { consuming food }\end{array}$ & $10(9.9)$ & $5(5)$ & 0.18 \\
\hline 2. & Nausea & $7(6.9)$ & $6(5.9)$ & 0.77 \\
\hline 3. & Horrifying dreams & $5(5)$ & $3(3)$ & 0.72 \\
\hline 4. & Dizziness & $2(2)$ & $1(1)$ & 0.50 \\
\hline 5. & Shivering of hands & $5(5)$ & $2(2)$ & 0.44 \\
\hline 6. & Fright & $2(2)$ & $1(1)$ & 0.50 \\
\hline 7. & $\begin{array}{l}\text { Lack of } \\
\text { concentration }\end{array}$ & $0(0)$ & $2(2)$ & - \\
\hline 8. & $\begin{array}{l}\text { Sleep } \\
\text { disturbances }\end{array}$ & $5(5)$ & $2(2)$ & 0.44 \\
\hline
\end{tabular}

\section{RESULTS}

All the 178 students completed the questionnaire. The results of questionnaire showed males $(n=101,56.74 \%)$ and females $(\mathrm{n}=77,43.26 \%)$, with a mean age of 18.32 years.

Various physical symptoms taken into consideration were:-

1. Difficulty in consuming food:- Difficulty in consuming food was observed in 10 males $(9.9 \%)$ on initial exposure and in 5 males (5\%) after 3 months, whereas in females, the same was observed in 8 cases $(10.4 \%)$ on initial exposure and in 7 cases $(9.1 \%)$ after 3 months. No statistical significant difference was found between males and females and between initial exposure and after 3 months.

2. Nausea:- Nausea was observed in 7 males $(6.9 \%)$ on initial exposure and in 6 males (5.9\%) after 3 months, whereas in females, the same was observed in 7 cases $(9.1 \%)$ on initial exposure and in 3 cases $(3.9 \%)$ after 3 months. No statistical significant difference was found between males and females and between initial exposure and after 3 months.

3. Horrifying dreams:- Horrifying dreams was observed in 5 males $(5 \%)$ on initial exposure and in 3 males $(3 \%)$ after 3 months, whereas in females, the same was observed in 5 cases $(6.5 \%)$ on initial exposure and in 2 cases $(2.6 \%)$ after 3 months. No statistical significant difference was found between males and females and between initial exposure and after 3 months.

4. Dizziness:- Dizziness was observed in 2 males (2\%) on initial exposure and in 1 male (1\%) after 3 months, whereas in females, the same was observed in 4 cases $(5.2 \%)$ on initial exposure and in 1 case $(1.3 \%)$ after 3 months. No statistical significant difference was found between males and females and between initial exposure and after 3 months.

5. Shivering of hands:- Shivering of hands was observed in 5 males $(5 \%)$ on initial exposure and in 2 males $(2 \%)$ after 3 months, whereas none of the females presented with shivering of hands on initial exposure as well as after 3 months. No statistical significant difference was found in males between initial exposure and after 3 months.

6. Fright:- Fright was observed in 2 males $(2 \%)$ on initial exposure and in 1 male $(1 \%)$ after 3 months, whereas in females, the same was observed in 3 cases $(3.9 \%)$ on initial exposure and in none of the females after 3 months. No statistical significant difference was found between males and females and between initial exposure and after 3 months.

7. Lack of concentration:- Lack of concentration was observed in none of the males on initial exposure and 
in 2 males $(2 \%)$ after 3 months, whereas in females, the same was observed in 4 cases $(5.2 \%)$ on initial exposure and in 3 cases $(3.9 \%)$ after 3 months. No statistical significant difference was found between males and females and between initial exposure and after 3 months.

8. Sleep disturbances:- Sleep disturbances was observed in 5 males $(5 \%)$ on initial exposure and in 2 males $(2 \%)$ after 3 months, whereas in females, the same was observed in 6 cases $(7.8 \%)$ on initial exposure and in none of the females after 3 months. No statistical significant difference was found between males and females and between initial exposure and after 3 months.

On initial exposure to dissection, all physical symptoms were observed more in females except shivering of hands which was more in males. After 3 months of dissection, difficulty in consuming food, dizziness and lack of concentration were more in females. All physical symptoms were found to be decreased over a period of 3 months in both males and females except lack of concentration in males which increased from $0 \%$ to $2 \%$. Percentage of asymptomatic students increased from $77 \%$ to $85.4 \%$ in this period of 3 months (Males from $78.2 \%$ to $85.1 \%$ and Females from $75.3 \%$ to $85.7 \%$ ).

\section{DISCUSSION}

Adverse physical and psychological effects to human dissection have been reported particularly in European, American and Canadian students. ${ }^{8}$ Jewish historical and scholarly writings have addressed the problematic relationship between anatomical dissection for the purpose of medical education and Judaism, which values the wholeness and sanctity of the human body. ${ }^{9}$

In the present study, we found that most of the students were asymptomatic at both the times the questionnaire was given.

These findings are consistent with those of O'Carroll et al, ${ }^{10}$ Vijayabhaskar et al, ${ }^{11} \mathrm{McG}$ arvey et $\mathrm{al}^{8}$ and Rajkumari et $\mathrm{al}^{12}$ who found that most of the first year medical students found their first visit to the anatomy dissection room exciting and suffered very little or no stress at all.

Attitudes towards dissection are also influenced by gender. Agnihotri and Sagoo reported that females were more apprehensive before entering the dissection hall in comparison to males and female: Male symptom ratio in dissection hall was 1.96:1 (nearly 2 times). They found that symptoms like Nausea, weakness, fright and lack of concentration were decreased over a period of 6 weeks, but the symptoms such as dizziness and restlessness were found to be increased. ${ }^{13}$

On the other hand, Javadnia et al reported higher percentage of symptoms in medical students on exposure to dissection hall like nausea in $29 \%$, lack of concentration in $38.7 \%$ and fright in $32 \%$ of the medical students. They found that symptoms like Nausea, weakness, fright and lack of concentration were decreased over a period of 6 weeks, but the symptoms such as dizziness and restlessness were found to be increased. ${ }^{14}$

Dubhashi et al reported much higher percentage of symptoms like sleep disturbances in $84 \%$, horrifying dreams in $45 \%$, difficulty in consuming food in $38 \%$ and fright in $30 \%$ of the medical students which is not consistent with the present study. ${ }^{15}$ The discussion is ending abruptly, please rewrite this paragraph to end the discussion more appropriately.

Tschernig et al reported that emotional issues during human dissection should not be neglected but addressed repeatedly. The authors feel that more attention should be paid to the first encounter with cadavers and students should be offered the opportunity to discuss their emotions. The students should be advised to prepare mentally and emotionally before entering the dissection room so that they are emotionally involved and stimulated. ${ }^{16}$

\section{CONCLUSION}

The results of this study clearly indicates that for most of the students, exposure to dissection hall is an intriguing and challenging experience which they perceive as a memorable event in their medical education and life.

Students experience various physical and psychological problems associated with cadaveric dissection, but these can be decreased by taking following interventions:-

A. Organizing orientation programs by clinical psychologist along with anatomist.

B. Group discussions with faculty members regarding their problems.

C. Better teacher-student interaction.

\section{REFERENCES}

1. Parker LM. What's wrong with the dead body? Use of the human cadaver in medical education. Med J Aust 2002; 176(2): 74- 76.

2. Mclachian J, Bradley $P$, Searle $\mathrm{J}$ and Bligh J. Teaching anatomy without cadavers. Med Edu 2004; 38: 418-424.

3. Gillingwater TH. The importance of exposure to human material in anatomical education: A philosophical perspective. Nat Sci Educ 2008; 1(6): 264-266. 
4. Newel RLM. Follow the royal road: The case for dissection. Clin Anat 1995; 8: 124-127.

5. Bertman SL and Marks SC. Humanities in medical education: Rationale and resources for the dissection laboratory. Med Edu 1985; 19(5): 374-381.

6. Cahill KC and Ettarh RR. Attitudes to anatomy dissection in an Irish medical school. Clin Anat 2009; 22(3): 386-391.

7. Dinsmore CE, Daugherty $S$ and Zeitz HJ. Student responses to the gross anatomy laboratory in a medical curriculum. Clin Anat 2001; 14(3): 231-236

8. Mc Garvey MA, Farrell T, Conroy RM, Kandiah $S$ and Monkhouse WS. Dissection: A positive experience. Clin Anat 2001; 14(3): 227-230

9. Notzer N, Zisenwine D, Oz L and Rak Y. Overcoming the tension between scientific and religious views in teaching anatomical dissection: The Israeli experience. Clin Anat 2006 Jul; 19(5): 442-447.

10. O'Caroll RE, Whiten S, Jackson D and Sinclair DW. Assessing the emotional impact of cadaver dissection on medical students. Med Edu 2002; 36(6): 550-554.
11. Vijayabhaskar P, Shankar PR and Dubey A. Emotional impact of cadaver dissection: A survey in a medical college in western Nepal. Kathmandu Univ Med J 2005; 3: 143-148.

12. Rajkumari A, Das BK, Sangma GTN and Singh YI. Attitudes and views of first year medical students towards cadaver dissection in anatomy learning. Calicut Med J 2008; 6(4):1-6.

13. Agnihotri $G$ and Sagoo MS. Reactions of first year Indian medical students to the dissection hall experience. NJIRM 2010; 1(4): 4-9.

14. Javadnia $F$, Hashemitabar $M$, Kalantarmahdavi $S R$ and Khajehmougahi N. How to decrease the emotional impact of cadaver dissection in medical students. Pak J Med Sci 2006; 22 (2): 200-203.

15. Dubhashi S, Dubhashi U, Singh A and Trinath T. Medical students react to cadaveric dissections. Rec Res Sci Tech 2011; 3(1): 135-138.

16. Tschernig $T$, Schlaud $M$ and Pabst $R$. Emotional reactions of medical students to dissecting room bodies: A conceptual approach and its evaluation. Anatomical Rec. Part B: New Anatomist 2000; 261: 11-13.

\section{Authors Contribution:}

RS - Concept and design of the study, collected data, reviewed the literature, manuscript preparation and critical revision of the manuscript; UV - Concept, collected data and review of literature and helped in preparing first draft of manuscript; PM - Conceptualized study, literature search, prepared first draft of manuscript and critical revision of the manuscript; PC - Concept of study, statistically analyzed and interpreted and review of study; SY - Concept of study, helped in collecting data and critical revision of manuscript.

Source of Support: Nil, Conflict of Interest: None declared. 